\title{
Prognostic significance of p21, p27 and survivin protein expression in patients with oral squamous cell carcinoma
}

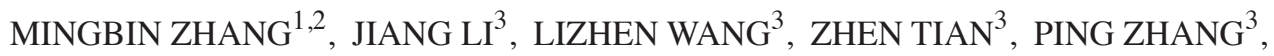 \\ QIN XU $^{3}$, CHENPING ZHANG $^{3}$, FENGCAI WEI $^{1}$ and WANTAO CHEN ${ }^{3}$ \\ ${ }^{1}$ School Of Stomatology, Shandong University, Jinan, Shandong 250012; ${ }^{2}$ Department of Stomatology, \\ Tai'an City Central Hospital, Tai'an, Shandong $271000 ;{ }^{3}$ Shanghai Key Laboratory of Stomatology, \\ Ninth People's Hospital, Shanghai Jiao Tong University School of Medicine, Shanghai 200011 P.R. China
}

Received January 21, 2013; Accepted May 23, 2013

DOI: $10.3892 / 01.2013 .1381$

\begin{abstract}
Oral squamous cell carcinoma (OSCC) accounts for $>80 \%$ of head and neck malignancies. p21, p27 and survivin proteins are abnormally expressed in OSCC and have been previously reported to correlate with cell proliferation and apoptosis. However, the prognostic significance of p21, p27 and survivin remains controversial. The aim of the present study was to investigate the association of clinical parameters and prognosis with the levels of p21, p27 and survivin expression in patients with OSCC. The levels of the three biomarkers were evaluated by immunohistochemical staining in specimens from 110 patients with OSCC and each section was scored according to the percentage of positive tumor cells and staining intensity. Log-rank test and Cox proportional hazards regression were performed to assess the correlation between biomarkers and clinical events. The association between the immunoexpression of p21, p27 and survivin and clinical pathological variables were analyzed by the $\chi^{2}$ test and a non-parametric analysis. The expression of $\mathrm{p} 21$ in patients with OSCC was found to correlate with the expression of p27 and survivin. The results of the current study revealed that the five-year survival rate was significantly lower in patients with high p21 expression. In addition, the expression of p27 also showed a negative correlation with the five-year survival rate of OSCC, but to a lesser extent. By contrast, the expression of survivin was not a prognostic factor for OSCC. A Kaplan-Meier analysis and Cox propor-
\end{abstract}

Correspondence to: Professor Fengcai Wei, School Of Stomatology, Shandong University, 44-1 Wenhuaxi Road, Jinan, Shandong 250012, P.R. China

E-mail:wfc1949@126.com

Professor Wantao Chen, Shanghai Key Laboratory Of Stomatology, Ninth People's Hospital, Shanghai Jiao Tong University School Of Medicine, 639 Zhizaoju Road, Shanghai 200011, P.R. China E-mail: chenwantao2002@hotmaill.com

Key words: p21, p27, survivin, oral squamous cell carcinoma, biomarker, prognosis tional hazards model showed that lymph node metastasis and p21 expression were independent prognostic factors of OSCC.

\section{Introduction}

Oral squamous cell carcinoma (OSCC) is the most prevalent pathological oral cancer, accounting for $>80 \%$ of head and neck malignancies (1). The carcinogenesis of OSCC is a multistage process involving the activation of oncogenes and the inactivation of tumor suppressor genes, with a cellular imbalance between cell death and growth. Regulators of apoptosis and the cell cycle may be important for the cellular balance of cell death and growth in cancer.

p21, p27 and survivin proteins have been identified to be abnormally expressed in the majority of human forms of cancer, including oral carcinoma. These expression levels usually correlate with cell proliferation and apoptosis, which contribute to the molecular carcinogenesis of cancer (2-5). The overexpression of p21 and p27 enhances the binding to cyclin-CDK complexes, which inhibits cell proliferation (6). Previous studies have shown that, in conjunction with survivin, p21 and p27 may also inhibit cell apoptosis $(7,8)$. The correlation between patient prognosis and biomarker expression has received considerable interest, however, the clinical implications and prognostic value of this correlation remain controversial due to the complex mechanisms of carcinogenesis and limitations with regard to small sample sizes and short follow-up periods (9-13). In the current study, the long-term follow-up of p21, p27 and survivin immunoexpression was extensively monitored in 110 patients with OSCC to examine the association with prognosis.

\section{Material and methods}

Study participants. p21, p27 and survivin expression levels were identified in formalin-fixed and paraffin-embedded specimens from 110 OSCC patients admitted to the Department of Oral and Maxillofacial Surgery (The Ninth People's Hospital, Shanghai Jiao Tong University School of Medicine, Shanghai, China) between 1989 and 1993. Oral mucosa samples from 20 healthy participants were included as controls. All individuals were treated by standard radical surgery with negative margins, and patients who were classified with T3, T4 or 
lymph node metastasis, according to the International Union Against Cancer TNM classification (14), were treated with 50-65 Gy radiotherapy post-operatively. Patients were followed up for $>5$ years. The mean age and range of the patients was 58 and 37-78 years-old, respectively. Gender, pathological grade and clinical stage are shown in Table I. Pathological grade was independently evaluated by three experienced pathologists. This study was approved by the ethics committee of The Ninth People's Hospital, Shanghai Jiao Tong University School of Medicine, Shanghai, China. Written informed consent was obtained from the patient's family.

Immunohistochemical staining. Immunostaining for p21 (ZM-0206), p27 (ZM-0340) and survivin (ZA-O530) was performed using reagents from Beijing Zhongshan Golden Bridge Biotechnology Co., Ltd. (Beijing, China) according to the manufacturer's instructions. Sections were dewaxed in xylene and rehydrated in graded alcohol prior to pretreatment with $0.3 \%$ hydrogen peroxide in phosphate-buffered saline (PBS) for 15 min to block endogenous peroxidase. Following this, a further 3 PBS washes were performed. The dewaxed sections were heated in a microwave oven in $10 \mathrm{mM}$ citric acid buffer (pH 6.0) for $15 \mathrm{~min}$ and gradually cooled down to room temperature. The sections were incubated with appropriate antibodies (mouse anti-human p21, p27 and rabbit anti-human survivin) overnight in a humidified chamber at $4^{\circ} \mathrm{C}$. The sections were then washed 3 times with PBS and incubated for $1 \mathrm{~h}$ at room temperature in a humidified chamber with a corresponding second antibody (goat anti-mouse and goat anti-rabbit), followed by being washed with PBS. Next, the sections were washed with a developing solution containing $0.06 \%$ diaminobenzidine and $0.1 \%$ hydrogen peroxide and then counterstained with hematoxylin and mounted. The sections without primary antibodies or with non-immunized rabbit serum for p21, p27 and survivin were included as the negative controls.

The sections were examined microscopically by three pathologists and scored according to the fraction of stained tumor cells and the staining intensity (Table II). The mean of each protein expression level was used as a cut-off value to define high and low expression (15), for example, p21 expression was high if the p21 score was $>2.7$ and low if $\leq 2.7$. Similarly, the p27 and survivin cut-off values were 2.8 and 2.0, respectively.

Statistical analysis. The results were analysed using SAS package version 9.2 (SAS Institute Inc., Cary, NC, USA). Prognostic factors were evaluated by univariable and multivariable analyses in the Cox proportional hazards model, and the correlation between all the parameters was analyzed using Pearson's correlation. $\mathrm{P}<0.05$ was considered to indicate a statistically significant difference.

\section{Results}

Expression of p21 and p27 in OSCC cells. The majority of p21 expression was localized in the nucleus of the OSCC cells and was identified by dark staining (Fig. 1A). The percentage of cells with positive p21 expression was $64.55 \%$ with a mean score of $2.7 \pm 0.8$. A log-rank test showed that the five-year survival rate of patients with elevated p21 expression levels was significantly lower when compared with that of patients
Table I. Baseline characteristics of OSCC patients.

\begin{tabular}{lcc}
\hline Clinical observations & $\mathrm{n}$ & Percentage \\
\hline Gender & & \\
Male & 59 & 53.64 \\
Female & 51 & 46.36 \\
Age, years & & \\
<60 & 75 & 68.18 \\
$>60$ & 35 & 31.82 \\
Tumor size & & \\
T1 & 14 & 12.73 \\
T2 & 53 & 48.18 \\
T3 & 16 & 14.55 \\
T4 & 27 & 24.54 \\
Lymph node metastasis & & \\
N0 & 82 & 74.55 \\
N1 & 25 & 22.73 \\
N2 & 3 & 2.72 \\
Pathological grading & & \\
I-II & 94 & 14.55 \\
III & 16 & \\
\hline
\end{tabular}

The tumor size is according to the TNM classification grade. OSCC, oral squamous cell carcinoma.

Table II. Classification standard for immunohistochemical staining of p21, p27 and survivin, evaluation and expression score calculation.

\begin{tabular}{lc}
\hline Standard & Scor \\
\hline Percentage & \\
0 & 0 \\
5 & 1 \\
$\leq 25$ & 2 \\
$\leq 50$ & 3 \\
$>50$ & 4 \\
Intensity & \\
Negative & 0 \\
Weak & 1 \\
Moderate & 2 \\
Intense & 3
\end{tabular}

with low p21 expression levels $(60.56 \pm 5.80$ vs. $82.05 \pm 6.15 \%$; $\mathrm{P}=0.0222$; Fig. 2A). Similarly, the majority of p27 expression was localized in the nucleus of the OSCC cells, however, the staining intensity was moderate (Fig.1B). The percentage of cells with positive p27 expression was $55.46 \%$, with a mean score of $2.8 \pm 0.9$. Patients with an elevated p27 level exhibited a lower five-year survival rate when compared with that of patients with lower p27 expression levels (63.93 \pm 6.15 vs. $73.47 \pm 6.31 \%$; $\mathrm{P}=0.2777$ ), however, this was not statistically significant (Fig. 2B). 
Table III. Pearson's correlation between parameters observed in patients with OSCC.

\begin{tabular}{lrrrrrrrr}
\hline Parameter & Gender & Age & Pathological grade & Tumor size & Node metastasis & p21 & p27 & Survivin \\
\hline Gender & 1.000 & -0.002 & -0.030 & 0.182 & -0.023 & -0.022 & 0.128 & 0.190 \\
Age, years & -0.002 & 1.000 & -0.056 & 0.051 & 0.049 & -0.153 & -0.104 & -0.182 \\
Pathological grade & -0.030 & -0.056 & 1.000 & 0.100 & -0.082 & 0.104 & 0.106 & -0.039 \\
Tumor size & 0.182 & 0.051 & 0.100 & 1.000 & 0.229 & -0.027 & 0.050 & -0.011 \\
Node metastasis & -0.023 & 0.049 & -0.082 & 0.229 & 1.000 & -0.120 & 0.006 & 0.044 \\
p21 & -0.022 & -0.153 & 0.104 & -0.027 & -0.120 & 1.000 & 0.210 & 0.292 \\
p27 & 0.128 & -0.104 & 0.106 & 0.050 & 0.006 & 0.210 & 1.000 & 0.212 \\
Survivin & 0.190 & -0.182 & -0.039 & -0.011 & 0.044 & 0.292 & 0.212 & 1.000 \\
\hline
\end{tabular}

Tumor size is according to the TNM classification grade. OSCC, oral squamous cell carcinoma.

A

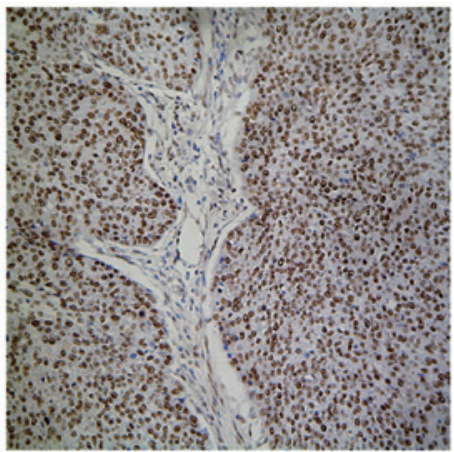

B

C
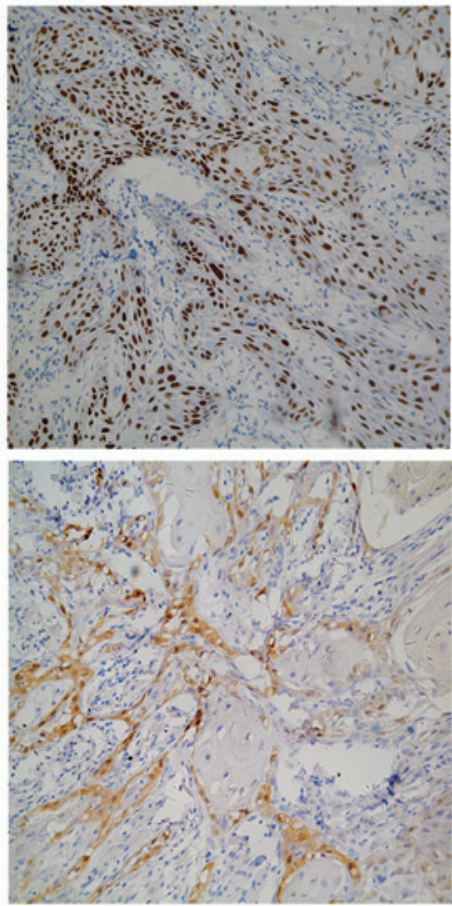

Figure 1. Immunohistochemical staining of (A) p21 and (B) p27 in OSCC, observed in the nuclei. (C) Staining of survivin located in the cytoplasm. Magnification, x100. OSCC, oral squamous cell carcinoma.

Expression of survivin in OSCC cells. By contrast, the majority of survivin was expressed in the cytoplasm of the OSCC cells, with negligible detection in the nucleus (Fig. 1C). The percentage of cells with positive survivin expression was $64.55 \%$, with a
A

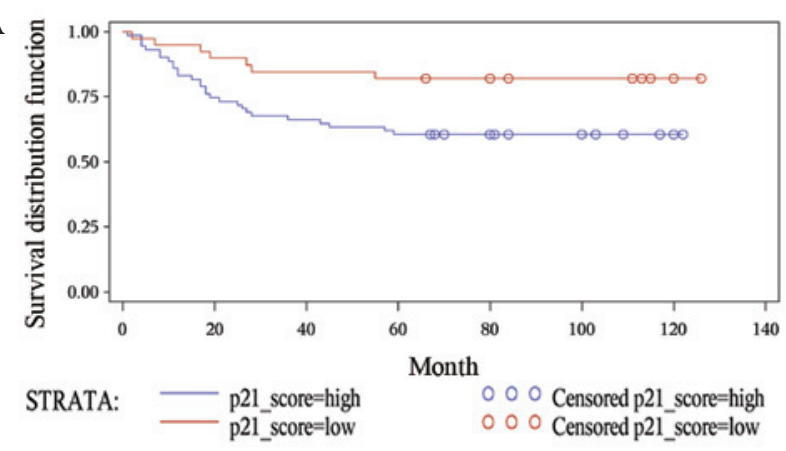

B

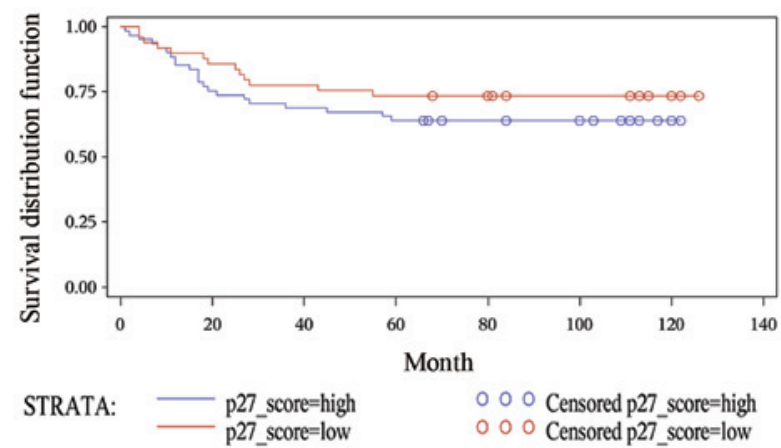

C

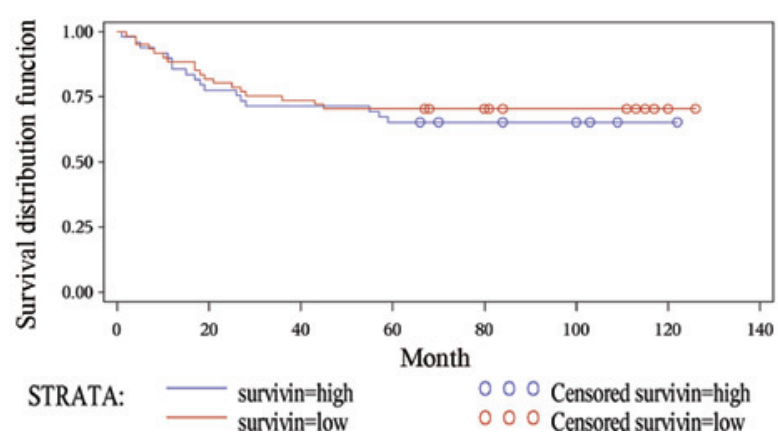

Figure 2.Kaplan-Meier plots for high vs. low expression of (A) p21 (B) p27 and (C) survivin in patients with OSCC. OSCC, oral squamous cell carcinoma.

mean score of $2.0 \pm 1.0$. No significant difference was identified between the five-year survival rate of patients with an elevated level of survivin expression when compared with that of patients with lower survivin expression levels (65.31 \pm 6.80 vs. $70.49 \pm 5.84 \%$; P=0.5843; Fig. 2C). 
Table IV. Univariate analysis of prognostic factors for survival using the Cox proportional hazards model.

\begin{tabular}{lccc}
\hline $\begin{array}{l}\text { Clinicopathological } \\
\text { parameters }\end{array}$ & $\begin{array}{c}\text { 5-year survival } \\
\text { rate, } \%\end{array}$ & $\chi^{2}$ & P-value \\
\hline $\begin{array}{l}\text { Gender } \\
\text { Male }\end{array}$ & $66.10 \pm 6.16$ & 0.2087 & 0.6478 \\
Female & $70.59 \pm 6.38$ & & \\
Age, years & & & \\
$\quad \leq 60$ & $64.00 \pm 5.54$ & 1.8642 & 0.1721 \\
$>60$ & $77.14 \pm 7.10$ & & \\
Tumor size & & & \\
T1-T2 & $73.13 \pm 5.42$ & 1.8661 & 0.1713 \\
T3-T4 & $60.47 \pm 7.46$ & & \\
Node metastasis & & & \\
Positive & $75.61 \pm 4.74$ & 10.8832 & 0.0011 \\
Negative & $46.43 \pm 9.42$ & & \\
Pathology grading & & & \\
I-II & $70.21 \pm 4.72$ & 1.2445 & 0.2646 \\
III & $56.25 \pm 12.40$ & & \\
p21 expression & & & \\
$\leq 2.7$ & $82.05 \pm 6.15$ & 5.2307 & 0.0222 \\
$>2.7$ & $60.56 \pm 5.80$ & & \\
p27 expression & & & \\
$\leq 2.8$ & $73.47 \pm 6.31$ & 1.1783 & 0.2777 \\
$>2.8$ & $63.93 \pm 6.15$ & & \\
Survivin expression & & & \\
$\leq 2.0$ & $70.49 \pm 5.84$ & 0.2993 & 0.5843 \\
$>2.0$ & $65.31 \pm 6.80$ & & \\
\hline
\end{tabular}

Tumor size is according to the TNM classification grade.

Correlation between p21, p27 and survivin and various parameters, and the univariate analysis results. The Pearson's correlation analysis (Table III) revealed that $\mathrm{p} 21$ expression significantly correlated with p27 $(\mathrm{r}=0.210 ; \mathrm{P}=0.026)$ and survivin ( $\mathrm{r}=0.292 ; \mathrm{P}=0.002)$ expression. In addition, there was a significant correlation between lymph node metastasis and tumor size ( $\mathrm{r}=0.229 ; \mathrm{P}=0.016)$. However, statistical correlations were not found between the immunoexpression of $\mathrm{p} 21$, p27 and survivin and age, gender, tumor size, lymph node metastasis or pathological grade $(\mathrm{P}>0.05)$.

The univariate analysis indicated that among the observed variables, only p21 expression and the status of lymph node metastasis were associated with the prognosis of patients with OSCC (Table IV).

\section{Discussion}

p21 and p27 are members of the Cip/Kip gene family that inhibit cell cycle progression by binding cyclin/Cdk complexes, thus functioning as regulators of cell cycle progression at the $\mathrm{G}_{1}$ stage $(16,17)$. In addition, the Cip/Kip family has been identified to activate the cyclin D/Cdk4 complex (18-22). p21 is capable of stabilizing the Cdk4-cyclin D interaction and promoting the formation of active complexes in a dosage-dependent manner (19). p21 may also regulate apoptosis $(23,24)$ through interactions with p27 and survivin (7,8). p21 functions as an inhibitor of apoptosis in a number of systems, which may counteract its tumor-suppressive function as a growth inhibitor (25). p21 has been reported to regulate apoptosis via p53-dependent and -independent pathways (26-28).

In the present study, the percentage of $\mathrm{p} 21$ and $\mathrm{p} 27$-positive cells was $\sim 64.55$ and $55.46 \%$, respectively. The results showed that the expression of $\mathrm{p} 21(\mathrm{P}=0.0222)$ and $\mathrm{p} 27(\mathrm{P}=0.2777)$ negatively correlated with prognosis, however, this was not statistically significant for $\mathrm{p} 27$. The present study demonstrated that the five-year survival rate of patients with a p21 expression score of $>2.7$ was significantly lower when compared with that of patients with a score of $\leq 2.7$, inconsistent with the majority of previous studies in OSCC $(10,11)$ and other types of cancer (29-34). However, certain other controversial results have also been reported (35-37).

Survivin is a member of the inhibitor of apoptosis protein family, and specific expression levels of survivin have been identified in embryogenesis and tumor cells (38-40). Survivin has been shown to be involved in cell division, anti-apoptosis and cell cycle control (40-44), and it has been hypothesized that survivin interacts with $\mathrm{p} 21$ to regulate cell apoptosis $(7,8)$. The survivin-p21 axis is important for the proliferation of normal hematopoietic cells and in the regulation of apoptosis through the p21WAF1/Cip1-dependent pathway (45). In the current study, the percentage of cells with survivin expression was $\sim 64.55 \%$, similar to results from previous studies (46). However, inconsistent with these previous results, survivin was not found to be an independent prognostic factor of OSCC $(47,48)$.

The expression of $\mathrm{p} 53$ and Bcl-2 was also examined in the samples (data not shown) and, notably, p21 expression was shown to be correlated with $\mathrm{p} 27$, survivin and Bcl-2, but not p53, indicating that p21 may function in a p53-independent manner in OSCC. The coexpression patterns among p21, p27, Bcl-2 and survivin demonstrated that $\mathrm{p} 21$ plays a predominant role in inhibiting apoptosis, likely through interactions with p27 and survivin $(7,8)$. In addition, p21-expressing cells may produce antiapoptotic proteins that affect the survival of adjacent cells through a paracrine effect (49). It has also been hypothesized that by inhibiting apoptosis in OSCC, p21 may enable tumor cells to accumulate for cell proliferation and may also present resistance to therapy by inhibiting treatment-related apoptosis, resulting in a reduced five-year survival rate (50). This may explain the negative correlation between the overexpression of p21 and prognosis.

In conclusion, the current study reveals that the prognosis of OSCC may be affected by a number of clinical pathological factors and biomarkers, among which, p21 plays an important role by inhibiting cell apoptosis or resistance to therapy. To improve overall survival rates, patients with a high $\mathrm{p} 21$ expression level must be administered intensive combined therapy and provided with follow-ups at an increased frequency.

\section{Acknowledgements}

This study was supported by grants from the Projects of the Shanghai Science and Technology Committee 
(nos. 08JC1414400, 10XD1402500, 11DZ2291800 and 10DZ1951300). The authors would like to thank the participants of the study.

\section{References}

1. Landis SH, Murray T, Bolden S and Wingo PA: Cancer statistics, 1999. CA Cancer J Clin 49: 8-31, 1999.

2. Coqueret O: New roles for p21 and p27 cell-cycle inhibitors: a function for each cell compartment? Trends Cell Biol 13: 65-70, 2003.

3. Bandoh N, Hayashi T, Takahara M, et al: Loss of p21 expression is associated with p53 mutations and increased cell proliferation and p27 expression is associated with apoptosis in maxillary sinus squamous cell carcinoma. Acta Otolaryngol 125: 779-785, 2005.

4. Lu Y and Cao W: The role of p21 (wafl/cip1) in human colorecta carcinoma cell apoptosis. Zhonghua Yi Xue Za Zhi 81: 1330-1332, 2001 (In Chinese).

5. Bissonnette $\mathrm{N}$ and Hunting DJ: p21-induced cycle arrest in G1 protects cells from apoptosis induced by UV-irradiation or RNA polymerase II blockage. Oncogene 16: 3461-3469, 1998.

6. Ravitz MJ and Wenner CE: Cyclin-dependent kinase regulation during G1 phase and cell cycle regulation by TGF-beta. Adv Cancer Res 71: 165-207, 1997.

7. Suzuki A, Ito T, Kawano H, et al: Survivin initiates procaspase 3/p21 complex formation as a result of interaction with Cdk4 to resist Fas-mediated cell death. Oncogene 19: 1346-1353, 2000.

8. Temme A, Diestelkoetter-Bachert P, Schmitz M, et al: Increased p21(ras) activity in human fibroblasts transduced with survivin enhances cell proliferation. Biochem Biophys Res Commun 327: 765-773, 2005 .

9. Xie X, Clausen OP and Boysen M: Prognostic significance of p21WAF1/CIP1 expression in tongue squamous cell carcinomas. Arch Otolaryngol Head Neck Surg 128: 897-902, 2002.

10. Fischer CA, Jung M, Zlobec I, et al: Co-overexpression of p21 and Ki-67 in head and neck squamous cell carcinoma relative to a significantly poor prognosis. Head Neck 33: 267-273, 2011.

11. Nemes JA, Nemes Z and Márton IJ: p21WAF1/CIP1 expression is a marker of poor prognosis in oral squamous cell carcinoma. J Oral Pathol Med 34: 274-279, 2005.

12. Zhuang Y, Yin HT, Yin XL, Wang J and Zhang DP: High p27 expression is associated with a better prognosis in East Asian non-small cell lung cancer patients. Clin Chim Acta 412: 2228-2231, 2011

13. Kapranos N, Stathopoulos GP, Manolopoulos L, et al: p53, p21 and p27 protein expression in head and neck cancer and their prognostic value. Anticancer Res 21: 521-528, 2001.

14. O'Sullivan, B and Shah J: New TNM staging criteria for head and neck tumors. Seminars Surg Oncol 21: 30-42, 2003.

15. Zhang $\mathrm{M}$, Zhang $\mathrm{P}$, Zhang $\mathrm{C}$, et al: Prognostic significance of Bcl-2 and Bax protein expression in the patients with oral squamous cell carcinoma. J Oral Pathol Med 38: 307-313, 2009.

16. Harper JW, Adami GR, Wei N, Keyomarsi K and Elledge SJ The p21 Cdk-interacting protein Cip1 is a potent inhibitor of G1 cyclin-dependent kinases. Cell 75: 805-816, 1993.

17. Gu Y, Turck CW and Morgan DO: Inhibition of CDK2 activity in vivo by an associated $20 \mathrm{~K}$ regulatory subunit. Nature 366 : 707-710, 1993

18. Cheng M, Olivier P, Diehl JA, et al: The p21(Cip1) and p27(Kip1) CDK 'inhibitors' are essential activators of cyclin D-dependent kinases in murine fibroblasts. EMBO J 18: 1571-1583, 1999.

19. Zhang H, Hannon GJ and Beach D: p21-containing cyclin kinases exist in both active and inactive states. Genes Dev 8: 1750-1758, 1994.

20. Soos TJ, Kiyokawa H, Yan JS, et al: Formation of p27-CDK complexes during the human mitotic cell cycle. Cell Growth Differ 7: 135-146, 1996.

21. Blain SW, Montalvo E and Massagué J: Differential interaction of the cyclin-dependent kinase (Cdk) inhibitor p27Kip1 with cyclin A-Cdk2 and cyclin D2-Cdk4. J Biol Chem 272: 25863-25872, 1997.

22. LaBaer J, Garrett MD, Stevenson LF, et al: New functional activities for the p21 family of CDK inhibitors. Genes Dev 11: 847-862, 1997

23. Zhang Y, Fujita $\mathrm{N}$ and Tsuruo T: Caspase-mediated cleavage of p21Waf1/Cip1 converts cancer cells from growth arrest to undergoing apoptosis. Oncogene 18: 1131-1138, 1999.
24. Wang Z, Su ZZ, Fisher PB, Wang S, VanTuyle G and Grant S: Evidence of a functional role for the cyclin-dependent kinase inhibitor p21(WAF1/CIP1/MDA6) in the reciprocal regulation of PKC activator-induced apoptosis and differentiation in human myelomonocytic leukemia cells. Exp Cell Res 244: 105-116, 1998.

25. Gartel AL and Tyner AL: The role of the cyclin-dependent kinase inhibitor p21 in apoptosis. Mol Cancer Ther 1: 639-649, 2002.

26. Narayanan BA, Geoffroy O, Willingham MC, Re GG and Nixon DW: p53/p21(WAF1/CIP1) expression and its possible role in G1 arrest and apoptosis in ellagic acid treated cancer cells. Cancer Lett 136: 215-221, 1999.

27. Okaichi K, Wang LH, Sasaki J, Saya H, Tada M and Okumura Y: A point mutation of human p53, which was not detected as a mutation by a yeast functional assay, led to apoptosis but not $\mathrm{p} 21 \mathrm{Waf} 1 / \mathrm{Cip} 1 / \mathrm{Sdi1}$ expression in response to ionizing radiation in a human osteosarcoma cell line, Saos-2. Int J Radiat Oncol Biol Phys 45: 975-980, 1999.

28. Yan Q and Sage EH: Transforming growth factor-beta1 induces apoptotic cell death in cultured retinal endothelial cells but not pericytes: association with decreased expression of p21waf1/cip1. J Cell Biochem 70: 70-83, 1998.

29. Gunia S, Kakies C, Erbersdobler A, Hakenberg OW, Koch S and May M: Expression of p53, p21 and cyclin D1 in penile cancer: p53 predicts poor prognosis. J Clin Pathol 65: 232-236, 2012.

30. Taghavi N, Biramijamal F, Sotoudeh M, et al: Association of p53/p21 expression with cigarette smoking and prognosis in esophageal squamous cell carcinoma patients. World J Gastroenterol 16: 4958-4967, 2010.

31. Siu MK, Chan HY, Kong DS, et al: p21-activated kinase 4 regulates ovarian cancer cell proliferation, migration, and invasion and contributes to poor prognosis in patients. Proc Natl Acad Sci USA 107: 18622-18627, 2010.

32. Mineo TC, Ambrogi V, Cufari ME and Pompeo E: May cyclooxygenase-2 (COX-2), p21 and p27 expression affect prognosis and therapeutic strategy of patients with malignant pleural mesothelioma? Eur J Cardiothorac Surg 38: 245-252, 2010.

33. Ogino S, Nosho K, Shima K, et al: p21 expression in colon cancer and modifying effects of patient age and body mass index on prognosis. Cancer Epidemiol Biomarkers Prev 18: 2513-2521, 2009.

34. Hu TH, Tai MH, Chuah SK, et al: Elevated p21 expression is associated with poor prognosis of rectal stromal tumors after resection. J Surg Oncol 98: 117-123, 2008.

35. Hafkamp HC, Mooren JJ, Claessen SM, et al: P21 Cip1/WAF1 expression is strongly associated with HPV-positive tonsillar carcinoma and a favorable prognosis. Mod Pathol 22: 686-698, 2009.

36. Pasz-Walczak G, Kordek R and Faflik M: P21 (WAF1) expression in colorectal cancer: correlation with P53 and cyclin D1 expression, clinicopathological parameters and prognosis. Pathol Res Pract 197: 683-689, 2001.

37. Fillies T, Woltering M, Brandt B, et al: Cell cycle regulating proteins $\mathrm{p} 21$ and $\mathrm{p} 27$ in prognosis of oral squamous cell carcinomas. Oncol Rep 17: 355-359, 2007.

38. Adida C, Crotty PL, McGrath J, Berrebi D, Diebold J and Altieri DC: Developmentally regulated expression of the novel cancer anti-apoptosis gene survivin in human and mouse differentiation. Am J Pathol 152: 43-49, 1998.

39. Ambrosini G, Adida C, Sirugo G and Altieri DC: Induction of apoptosis and inhibition of cell proliferation by survivin gene targeting. J Biol Chem 273: 11177-11182, 1998.

40. Ambrosini G, Adida C and Altieri DC: A novel anti-apoptosis gene, survivin, expressed in cancer and lymphoma. Nat Med 3: 917-921, 1997.

41. Li F, Ackermann EJ, Bennett CF, et al: Pleiotropic cell-division defects and apoptosis induced by interference with survivin function. Nat Cell Biol 1: 461-466, 1999.

42. Kobayashi K, Hatano M, Otaki M, Ogasawara T and Tokuhisa T: Expression of a murine homologue of the inhibitor of apoptosis protein is related to cell proliferation. Proc Natl Acad Sci USA 96: 1457-1462, 1999.

43. Li F, Ambrosini G, Chu EY, et al: Control of apoptosis and mitotic spindle checkpoint by survivin. Nature 396: 580-584, 1998.

44. Suzuki A and Shiraki K: Tumor cell 'dead or alive': caspase and survivin regulate cell death, cell cycle and cell survival. Histol Histopathol 16: 583-593, 2001.

45. Fukuda S, Mantel CR and Pelus LM: Survivin regulates hematopoietic progenitor cell proliferation through p21WAF1/Cip1-dependent and -independent pathways. Blood 103: 120-127, 2004. 
46. Tanaka C, Uzawa K, Shibahara T, Yokoe H, Noma $\mathrm{H}$ and Tanzawa H: Expression of an inhibitor of apoptosis, survivin, in oral carcinogenesis. J Dent Res 82: 607-611, 2003.

47. Li C, Li Z, Zhu M, et al: Clinicopathological and prognostic significance of survivin over-expression in patients with esophageal squamous cell carcinoma: a meta-analysis. PloS One 7: e44764, 2012.

48. Ekeblad S, Lejonklou MH, Stálberg P and Skogseid B: Prognostic relevance of survivin in pancreatic endocrine tumors. World $\mathrm{J}$ Surg 36: 1411-1418, 2012.
49. Chang BD, Watanabe K, Broude EV, et al: Effects of p21Waf1/Cip1/Sdi1 on cellular gene expression: implications for carcinogenesis, senescence, and age-related diseases. Proc Nat Acad Sci USA 97: 4291-4296, 2000.

50. Schmidt $M$ and Fan Z: Protection against chemotherapy-induced cytotoxicity by cyclin-dependent kinase inhibitors (CKI) in CKI-responsive cells compared with CKI-unresponsive cells. Oncogene 20: 6164-6171, 2001. 